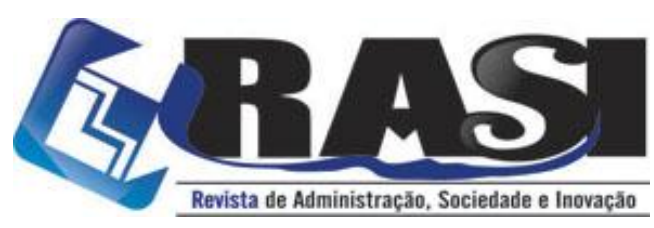

http://www.rasi.uff.br

RASI, Volta Redonda/RJ, v. 4, n. 2, pp. 183-203, jul./dez. 2018

\title{
Determinantes da Estrutura de Capital no Brasil: Evidências Empíricas a partir de Dados em Painel no período entre 2010 e 2016
}

\author{
Mario Cordeiro Filho (USCS) - mario.cordeiro@uol.com.br \\ João Batista Pamplona (USCS e PUC-SP) - pamplona@uscs.edu.br \\ Edimilson Costa Lucas (EPPEN-UNIFESP) - prof.eclucas@gmail.com \\ Ricardo Makoto Kawai (USCS) - ricardo.m.kawai@gmail.com
}

\begin{abstract}
RESUMO: Esse estudo analisa os fatores determinantes da estrutura de capital das companhias abertas brasileiras (exceto instituições financeiras e seguradoras) com ações listadas na BM\&BOVESPA no período de 2010 a 2016, sob a perspectiva da pecking order theory e da tradeoff theory, empregando metodologia de dados em painel e modelos econométricos com variáveis de controle referentes à tangibilidade dos ativos, ao porte das empresas, a oportunidades de crescimento e à rentabilidade dos ativos. Este artigo preenche lacuna relativa ao reduzido número de estudos correlatos no período objeto da análise e considera base de dados homogênea oriunda das demonstrações financeiras elaboradas de acordo com as normas internacionais de contabilidade a partir de 2010. Possíveis limitações desse artigo advêm do reduzido número de companhias brasileiras com ações listadas em bolsa, assim como o reduzido número de observações comparativamente aos estudos semelhantes, notadamente os focados no mercado de capitais norte-americano. Os resultados obtidos sugerem que as companhias abertas brasileiras se financiam substancialmente por meio da emissão de dívida, corroborando o modelo da pecking order theory. Não foram encontradas evidências robustas que sugiram que empresas sigam o modelo da tradeoff theory.
\end{abstract}

PALAVRAS-CHAVE: Estrutura de capital, Pecking Order Theory, e Tradeoff Theory.

\section{Determinants of Capital Structure in Brazil: Empirical Evidence from Panel Data in the period between} 2010 and 2016

ABSTRACT: This study analyzes the determinants of the capital structure of Brazilian public companies (excluding financial institutions and insurance companies) with shares listed on BM\&FBOVESPA between 2010 and 2016, from the perspective of pecking order theory and tradeoff theory, using data methodology in panel and econometric models with control variables related to the tangibility of the assets, the size of the companies, the growth opportunities and the profitability of the assets. This article fills in the gap related to the small number of correlated studies in the period of analysis and considers a homogeneous database derived from financial statements prepared in accordance with international accounting standards as of 2010. Possible limitations of this article come from the small number of Brazilian companies with shares listed on the stock exchange, as well as the small number of observations compared to similar studies, especially those focused on the US capital market. The results obtained suggest that Brazilian public companies are substantially financed through debt issuance, corroborating the pecking order theory model. No robust evidence was found to suggest that firms follow the tradeoff theory model.

KEYWORDS: Capital structure, Pecking Order Theory and Tradeoff Theory

\begin{tabular}{l}
\hline $\begin{array}{l}\text { Universidade } \\
\text { Federal } \\
\text { Fluminense }\end{array}$ \\
27213-415 - Volta Redonda, RJ - Brasil \\
www.uff.br \\
Copyright (C) 2018 RASI. Todos os direitos, até mesmo de tradução, são reservados. É \\
permitido citar parte de artigos sem autorização prévia, desde que seja identificada a fonte
\end{tabular}




\section{Determinantes da Estrutura de Capital no Brasil: Evidências Empíricas a partir de Dados em Painel no período entre 2010 e 2016}

\section{Introdução}

A estrutura de capital das empresas é um tema considerado proeminente, sendo apontada por Myers, Allen e Brealey (2017) como umas das questões mais importantes da literatura de finanças.

As teorias referentes ao tema estrutura de capital buscam explicar a proporção entre as fontes de recursos utilizadas pelas empresas para financiar os investimentos realizados, destacando-se os modelos pecking order theory e tradeoff theory conforme aponta Myers (2001).

Corroborando a importância do tema, Coelho (2015) tendo por objetivo investigar determinantes da estrutura de capital baseado nos modelos pecking order e tradeoff, identifica 76 produções científicas nacionais e internacionais no período de 2004 a 2013, sendo que mais de 50\% ocorreram no período entre 2011 e 2013. Nakamura e Nisiyama (2015) identificam 51 artigos relativos a estrutura de capital nas revistas The Review of Financial Studies, The Journal of Finance, Journal of Financial Economics e Journal of Banking \& Finance no período de 2011 a 2013, representando 2,8\% do total das publicações dos referidos periódicos e uma média de 14 artigos/ano.

A pesquisa empírica sobre este tema é focada na proporção entre dívida e ações empregada pelas empresas, e abrange diferentes mercados de capitais de diferentes países tal como apontado pelos estudos realizados por Frank e Goyal (2003), Fama e French (2005), Nakamura, Correa e Basso (2013), Oztekin (2015) e Coelho (2015).

Conforme Nakamura et al (2013) os resultados dos estudos não são convergentes o que sugere que o assunto não foi esgotado, ensejando a oportunidade de novas pesquisas sobre o tema.

Corroborando a ideia da necessidade de continuidade de pesquisas sobre o tema, Graham, Leary e Roberts (2015), em estudo realizado sobre a evolução da estrutura de capital das empresas norte americanas nos últimos cem anos, apontam que as empresas aumentaram o emprego de dívida, entretanto, as mudanças nas características das empresas ao longo do tempo não explicam as diferenças no padrão da estrutura de capital que passou a empregar mais dívida.

Posto isto, este estudo tem por objetivo analisar a estrutura de capital das companhias abertas brasileiras com ações listadas na BM\&FBOVESPA, (doravante denominadas companhias abertas brasileiras) no período de 2010 a 2016, sob as perspectivas da pecking order theory e tradeoff theory..

O período objeto deste estudo é caracterizado por reduzido crescimento da economia do Brasil, queda do índice BOVESPA, comparativamente aos quinquênios de 2000 a 2004, 2005 a 2009 e 2010 a 2014, conforme evidenciado na Tabela 1. 
Tabela 1. Médias anuais, em percentuais, de indicadores econômicos.

\begin{tabular}{lrrrrr}
\hline \multicolumn{1}{c}{ Períodos/Indicadores } & \multicolumn{1}{c}{ PIB } & Risco País & IBOVESPA & S\&P 500 & Dow Jones \\
\hline 2000 a 2004 & 3,00 & 8,39 & 8,92 & $-2,32$ & $-1,27$ \\
2005 a 2009 & 3,53 & 2,77 & 21,23 & 0,43 & $-0,67$ \\
2010 a 2014 & 2,22 & 1,66 & $-5,13$ & 12,59 & 9,35 \\
2015 a 2016 & $-3,49$ & 3,60 & 9,75 & 6,42 & 10,38 \\
2010 a 2016 & $-0,17$ & 2,16 & $-1,98$ & 10,49 & 9,40 \\
\hline
\end{tabular}

Fonte: Instituto Assaf (2017).

O período de 2012 a 2016 também é caracterizado por um montante menor de captação de recursos por meio de ofertas públicas de ações, em comparação com a oferta pública de debêntures, conforme indicado na Tabela 2.

Tabela 2. Ofertas públicas de ações e debêntures no Brasil, em R $\$$ bilhões, correntes.

\begin{tabular}{lrrrr}
\hline & \multicolumn{2}{c}{ Ações } & \multicolumn{2}{c}{ Debêntures } \\
\multicolumn{1}{c}{ Períodos/Indicadores } & Quantidade & Montante & Quantidade & Montante \\
\hline 2012 & 13 & 14,3 & 222 & 86,3 \\
2013 & 20 & 23,9 & 268 & 68,8 \\
2014 & 2 & 15,4 & 285 & 72,5 \\
2015 & 6 & 18,3 & 214 & 62,6 \\
2016 & 10 & 10,8 & 170 & 63,7 \\
TOTAL & 51 & 82,7 & 1.159 & 353,9 \\
\hline
\end{tabular}

Fonte: Comissão de Valores Mobiliários (2017).

A despeito das peculiaridades econômicas e do mercado de capitais referentes ao período de 2010 a 2016, cabe salientar que, em 2010, foram implantadas as Normas Internacionais de Contabilidade nas empresas brasileiras (exceto em instituições financeiras e seguradoras), permitindo que este estudo empregue uma base de dados homogênea referente às informações oriundas das demonstrações financeiras.

A Tabela 3 apresenta os problemas a serem respondidos neste artigo.

Tabela 3. Problemas de Pesquisa

\begin{tabular}{|c|c|}
\hline Problemas de Pesquisa & Perguntas formuladas \\
\hline Problema 1 & $\begin{array}{l}\text { 1. A estrutura de capital das companhias abertas } \\
\text { brasileiras segue o modelo pecking order theory? }\end{array}$ \\
\hline Problema 2 & $\begin{array}{l}\text { 2. A estrutura de capital das companhias abertas } \\
\text { brasileira segue o modelo tradeoff theory? }\end{array}$ \\
\hline
\end{tabular}

Fonte: elaboração própria.

\section{Fundamentação Teórica}

O tema estrutura de capital ganhou notoriedade no mundo das finanças com o estudo seminal de Modigliani e Miller (MM), conhecido como Proposição I de MM (Modigliani \& Miller, 1958) e sua posterior evolução, denominada Proposição II de MM (Modigliani \& Miller, 1963). 
De acordo com a Proposição I de MM, a proporção entre dívida e recursos dos acionistas, denominada alavancagem financeira, sob a premissa de um mercado de capitais perfeito, isto é, sob a ausência de custos de transações e de impostos sobre lucros, é indiferente do ponto de vista de valor das empresas. Já a Proposição II de MM assume a existência de imperfeições de mercado referentes a existência de impostos sobre os lucros, reconhecendo que a proporção dívida e recursos dos acionistas não é indiferente do ponto de vista de valor das empresas (Modigliani \& Miller, 1963)..

Posteriormente às Proposições I e II de MM, são desenvolvidos outros estudos relativos à estrutura de capital, destacando-se os modelos teóricos fundamentados em assimetria de informações, custos de agência, e impostos sobre os lucros.

\subsection{Estrutura de Capital, Assimetria de Informações e Impostos sobre os Lucros}

As principais premissas adotadas pelos referidos modelos baseados em assimetria de informações, custos de agência e impostos sobre os lucros são: a administração das empresas é separada da propriedade, as empresas se financiam por meio de lucros retidos, emissões de títulos de dívida e emissões de ações, as empresas são contribuintes de impostos sobre lucros, as despesas financeiras incorridas decorrentes de dívidas, são deduzidos da base de cálculo dos impostos sobre os lucros (debt tax shield), determinados itens não financeiros, como despesa de depreciação, amortização e exaustão, também são deduzidos da base de cálculo dos impostos sobre os lucros (non debt tax shield), e empresas podem ter oportunidades de crescimento por meio de investimentos (DeAngelo \& Masulis, 1980; Jensen \& Meckling, 1976; Jensen, 1986; Fama, 1980; Myers, 2001).

Considerando a assunção das premissas relativas às companhias, tem-se os agentes de mercado, no caso acionistas, credores, administradores e investidores, cujos direitos de decisões, interesses e acesso a informações podem influenciar as decisões de investimentos e financiamentos das empresas (Jensen \& Meckling, 1976; Jensen, 1986; Fama, 1980; Myers, 2001). Em decorrência das premissas assumidas, admite-se a existência de assimetria de informações e conflitos de interesses entre os agentes de mercado apontados (Jensen \& Meckling, 1976; Jensen, 1986; Harris \& Raviv, 1991; Myers, 2001).

Desta forma, os modelos teóricos de estrutura de capital fundamentados em assimetria de informações e custos de agência buscam explicar o impacto na estrutura de capitais decorrentes dos diferentes níveis de informações entre administradores, acionistas, credores e investidores têm entre si, e os respectivos custos de agência (Myers, 2001; Fama $\&$ French, 2002).

Titman e Wessels (1988), focando em companhias abertas norte-americanas, analisam o impacto sobre a estrutura de capital das empresas proporcionado pelo emprego de ativos tangíveis e os respectivos non debt tash shield, pelo crescimento, pela especificidade do negócio, pelos setores de atuação, pela volatilidade dos lucros, pelo porte e pela rentabilidade dos ativos. Segundo os autores, embora os resultados não sejam estatisticamente conclusivos, a pesquisa introduziu técnicas de análise da relação entre variáveis, contribuindo para estudos futuros.

Harris e Raviv (1991) pesquisaram diversas teorias sobre estrutura de capital, considerando potenciais determinantes de alavancagem financeira, o non debt tax shield decorrente do emprego de ativos tangíveis, as oportunidades de crescimento por meio de investimentos, o porte, a volatilidade dos lucros, a probabilidade de falência, a rentabilidade e a especificidade de produtos. 
De acordo com Harris e Raviv (1991), os estudos apontam que a alavancagem financeira aumenta com o emprego de ativos tangíveis, a existência de escudos fiscais de itens não financeiros, as oportunidades de crescimento e o porte das empresas. E a alavancagem financeira decresce com a volatilidade dos fluxos de caixa, as despesas de propaganda, as despesas de pesquisa e desenvolvimento, o risco de falência e a especificidade de produtos.

Rajan e Zingales (1995), em estudo empírico sobre companhias abertas do G-7 (Alemanha, Canadá, Estados Unidos da América, França, Grã-Bretanha, Itália e Japão), analisam os graus de alavancagem financeira, mensurada sob as perspectivas tanto do valor contábil quanto do valor de mercado, considerando o grau de tangibilidade dos ativos, o porte, as oportunidades de crescimento e o porte dos ativos. Apesar das diferenças verificadas entre os países objeto do estudo, os resultados alcançados estão em linha com as predições teóricas apontadas por Harris e Raviv (1991).

Para explicar as decisões de financiamento das empresas, a literatura de finanças foca em dois modelos que competem entre si, a saber: pecking order theory (POT) e tradeoff theory (TOT) (Myers, 2001; Fama \& French, 2002), cujos pressupostos teóricos são apresentados a seguir.

\subsection{Pecking Order Theory}

A POT, atribuída a Myers e Majluf (1984), surge como um modelo teórico que busca explicar a estrutura de capital das empresas e é tida como uma das teorias mais influentes sobre o assunto segundo Frank e Goyal (2003), sendo corroborados por Kumar, Colombage e Rao (2017) que apontam para a predominância da POT tanto do ponto de vista teórico quanto empírico..

O modelo teórico da POT abrange as empresas que detêm ativos em operação, têm oportunidades de crescimento por meio de investimentos e, consequentemente, demandam recursos financeiros para financiar os referidos processos de expansão (Myers, 2001).

Os pressupostos básicos desse modelo teórico são: as empresas têm acesso a mercados de capitais perfeitos, exceto pela assimetria de informações existente entre administradores e investidores, os investidores e administradores têm consciência da assimetria de informações existente entre ambos e os administradores atuam em defesa dos interesses dos acionistas (Myers, 2001).

Como consequência dos pressupostos adotados pela POT, os investidores não são capazes de precificar de forma adequada o valor justo de possíveis emissões de ações, e os administradores não emitem ações subavaliadas, exceto quando o valor presente líquido de um projeto de expansão for superior à transferência de valor dos acionistas atuais para os investidores em razão de eventual emissão de ações subavaliadas (Myers, 2001; Fama \& French, 2002).

Considerando o risco de transferência de ganhos ou perdas entre acionistas e investidores, decorrente da emissão de ações precificadas de forma inadequada, ou seja, sub ou superavaliadas, a emissão de títulos de dívida surge como uma alternativa plausível para suprir as necessidades de recursos das empresas (Myers, 2001).

Em razão de os credores assumirem menos riscos do que os investidores, uma eventual emissão de títulos de dívida seria menos afetada pela assimetria de informações e não teria um impacto desfavorável no valor da empresa (Myers, 2001). 
Diante do exposto, os administradores, para fins de financiamento de oportunidades de crescimento por meio da implantação de investimentos de expansão, seguem a seguinte ordem de prioridade na utilização de recursos: lucros retidos, emissões de títulos de dívida e emissões de ações (Myers \& Majluf, 1984; Myers \& Sunder, 1999; Myers, 2001; Fama \& French, 2002).

Em complementação à hierarquia das fontes de financiamentos, após esgotadas as fontes internas de recursos, uma emissão de dívida ocorrerá somente se puder ser feita a um preço justo, e as ações serão emitidas somente se os administradores tiverem a percepção de que a companhia está superavaliada ou se o nível de endividamento estiver alto a pon to de uma emissão de dívida se tornar muito cara ou se os administradores antevirem uma possível situação de financial distress (Myers, 2001).

Ainda sobre a necessidade de recursos, a POT não considera, no curto prazo, redução da distribuição dos lucros por meio de dividendos como fonte de recursos para financiar investimentos de expansão. Se os fundos internos não forem suficientes, a defasagem será obtida por meio de fundos externos (Myers \& Sunder, 1999; Myers, 2001; Fama \& French, 2002).

Adicionalmente, de acordo com a POT, ocorrendo superávits de caixa gerados internamente, estes serão utilizados a princípio para liquidar financeiramente dívidas, de preferência em relação à recompra de ações ou à redução de capital (Myers, 2001).

Quanto ao endividamento, a POT não define um nível ótimo. As dívidas das empresas refletem suas necessidades de financiamentos externos em relação aos fluxos de caixa decorrentes das operações, às oportunidades de investimentos e às políticas de dividendos praticadas (Myers \& Sunder, 1999; Myers, 2001; Fama \& French, 2002). A Tabela 4 evidencia as principais predições da POT.

Tabela 4. Principais Predições da POT

\begin{tabular}{|c|c|c|c|c|c|}
\hline $\begin{array}{c}\text { Variáveis de } \\
\text { Controle }\end{array}$ & Proxies & Dividendos & $\begin{array}{c}\text { Alavancagem } \\
\text { Financeira } \\
\text { (Valor Contábil } \\
\text { ou BV) }\end{array}$ & $\begin{array}{c}\text { Alavancagem } \\
\text { Financeira } \\
\text { (Valor de } \\
\text { Mercado ou } \\
\text { MV) }\end{array}$ & Referência \\
\hline $\begin{array}{c}1 . \\
\text { Rentabilidade } \\
\text { dos ativos (P) }\end{array}$ & $P=\frac{E B I T}{A}$ & $\begin{array}{l}\text { Controlando } \\
\text { oportunidades de } \\
\text { investimentos, } \\
\text { empresas mais } \\
\text { rentáveis pagam } \\
\text { mais dividendos } \\
\text { no longo prazo }\end{array}$ & $\begin{array}{l}\text { Controlando } \\
\text { oportunidades de } \\
\text { investimentos, } \\
\text { empresas mais } \\
\text { rentáveis têm } \\
\text { menor } \\
\text { alavancagem em } \\
\text { razão de terem } \\
\text { mais fundos } \\
\text { internos } \\
\text { disponíveis. }\end{array}$ & $\begin{array}{c}\text { Controlando } \\
\text { oportunidades } \\
\text { de } \\
\text { investimentos, } \\
\text { empresas mais } \\
\text { rentáveis têm } \\
\text { menor } \\
\text { alavancagem } \\
\text { em razão de } \\
\text { terem mais } \\
\text { fundos } \\
\text { internos } \\
\text { disponíveis. }\end{array}$ & $\begin{array}{l}\text { Myers e } \\
\text { Majluf } \\
\text { (1984) e } \\
\text { Myers } \\
(2001)\end{array}$ \\
\hline
\end{tabular}




\section{Variáveis de Controle \\ 3. Volatilidade dos fluxos de caixa livres \\ (FCF) \\ 4. Política de dividendos no curto prazo}

\section{Porte (LS) $L S$}

$$
=L O G R O
$$

Proxies

\title{
Dividendos
}

\begin{abstract}
Empresas com fluxos de caixa livres mais voláteis pagam menos

dividendos em razão de serem mais arriscadas
\end{abstract}

Diante da
redução de lucros
ou do surgimento
de oportunidades
de investimentos
no curto prazo,
os pagamentos
de dividendos
são mantidos

\section{Redução de} lucros ou do surgimento de oportunidades de investimentos no

\section{Alavancagem Financeira (Valor Contábil ou BV)}

Empresas com

fluxos de caixa livres mais voláteis têm menor alavancagem em razão de serem mais arriscadas

curto prazo, os pagamentos de dividendos são mantidos e a compensação financeira é feita por meio de maior alavancagem

Empresas de maior porte têm maior alavancagem financeira

Empresas que empregam menos ativos tangíveis têm mais problemas de assimetria de informações e, portanto, têm maior alavancagem

\section{Alavancagem \\ Financeira \\ (Valor de \\ Mercado ou MV)}

Referência

Myers e Majluf (1984) e Myers (2001)

Myers e Majluf (1984) e Myers (2001)

Harris e Raviv (1991) e Rajan e Zingales

(1995)

Harris e Raviv (1991) e Rajan e Zingales (1995)

Fonte: Adaptação baseada em Fama e French (2002).

Em que::

EBIT: lucro antes dos juros e dos impostos;

A: ativo total;

$F C F$ : fluxo de caixa livre;

LS: logaritmo da receita operacional anual; e 
AT: ativos tangíveis.

Uma vez evidenciadas as principais predições da POT, cumpre elucidar a questão das versões simples e complexa da POT, indicada na Tabela 4, item 2, Oportunidades de Investimentos (MTB).

Em relação às oportunidades de investimentos, sob a perspectiva da POT, quando as empresas têm oportunidades de investimento que demandam recursos além dos lucros retidos, há duas interpretações possíveis, . Nesta situação, na versão simplificada da POT as empresas buscam complementação de recursos por meio de fundos externos, na versão complexa da POT, as empresas restringem os investimentos em razão da preocupação do risco de assumir maior risco financeiro (Fama e French, 2002)

De acordo com Fama e French (2002), as evidências de que o nível de alavancagem é menor diante de oportunidades de investimentos são fortes. Isso pode ser interpretado em favor da versão complexa da POT sobre como os problemas de agência entre acionistas e credores podem afetar o nível de alavancagem financeira das empresas.

O modelo POT é objeto de críticas em relação à premissa de que os administradores atuam em defesa do interesse dos acionistas existentes. Esse modelo teórico não prevê a existência de incentivos aos administradores para justificar a atuação em defesa dos acionistas existentes. Tampouco pode explicar o porquê de não serem desenvolvidos meios para neutralizar a assimetria de informações que os administradores têm e que estão relacionadas ao valor da empresa e das oportunidades de crescimento (Myers, 2001).

Do ponto de vista empírico, Myers e Sunder (1999) analisaram companhias abertas norte-americanas no período entre 1971 e 1989, concluindo pela prevalência do modelo POT sobre o TOT.

Entretanto, Frank e Goyal (2003), considerando o mercado de capitais norteamericano, no período entre 1971 e 1998, concluem que, embora grandes empresas evidenciem alguns aspectos relacionados ao modelo POT, as evidências não são robustas e o financiamento dos déficits de caixa é menos importante para explicar emissões e recompras de ações para empresas de todos os tamanhos.

Fama e French (2005), também com base no mercado de capitais norte-americano e considerando o período entre 1973 e 2002, apontam que houve expressivos montantes de emissão e recompras de ações, contrariando os pressupostos da POT.

De acordo com Fama e French (2005), a predominância das emissões de ações observada no mercado de capitais norte-americano decorre da possibilidade de emissões com custos de transações mais baixos e com menor assimetria de informações, como emissão de ações para compra por empregados, e fusões entre empresas financiadas, por ações, explicando a relevante participação do financiamento fundamentado em ações, em contraposição às premissas da POT.

\subsection{Tradeoff Theory}

Conforme a TOT, empresas buscam um nível ótimo de alavancagem financeira, ponderando custos e benefícios marginais proporcionados pela utilização de recursos de terceiros na forma de dívida (Fama \& French, 2002). 
O primeiro benefício oriundo da utilização de dívidas é o decorrente do escudo fiscal proporcionado pelos impostos sobre os lucros economizados em razão da dedução dos juros incorridos das dívidas, para fins de cálculo do lucro tributável das empresas (Myers, 2001; Fama \& French, 2002).

O segundo benefício é a mitigação dos custos de agência decorrentes do conflito de interesses entre acionistas e administradores, em razão da redução dos fluxos de caixa livres por conta dos compromissos firmados com credores (amortização de principal e pagamento de juros), reduzindo, assim, o poder discricionário dos administradores na utilização dos fluxos de caixa gerados pelas empresas (Jensen \& Meckling, 1976; Jensen, 1986; Fama \& French, 2002).

Aos benefícios gerados pelo emprego de dívida, existem os possíveis custos de reorganização e falência incorridos quando a credibilidade financeira de uma empresa se torna duvidosa (situação de financial distress) e os custos de agência são decorrentes do conflito de interesses entre acionistas e credores (Myers, 2001; Fama \& French, 2002).

Ainda sobre a questão dos impostos sobre os lucros, cabe destacar o escudo fiscal decorrente de itens não financeiros (non debt tax shield), como força contrária ao escudo fiscal proporcionado pelos juros incorridos das dívidas, influenciando, portanto, o nível de alavancagem financeira das empresas (DeAngelo \& Masulis, 1980; Fama \& French, 2002).

A TOT também prevê que as empresas maximizem seu valor, distribuindo parte dos lucros por meio de dividendos até o ponto em que custos e benefícios dos recursos distribuídos se igualem, definindo, portanto, um ponto ótimo de pagamento de dividendos (Fama \& French, 2002).

Como resultado das premissas assumidas pela TOT, é esperado que empresas mais lucrativas empreguem uma proporção maior de dívida e distribuam mais lucros por meio de dividendos. Entretanto, os possíveis custos de falência e reorganização, além do conflito de interesses entre acionistas e credores, atuam como limitadores do aumento da alavancagem financeira (Myers, 2001; Fama \& French, 2002).

De acordo com a TOT, o nível ótimo de alavancagem financeira (target leverage) e o ponto ótimo de pagamento de dividendos (target payout) são conduzidos por vetores de forças contrárias e intensidades diversas que se contrapõem no atingimento dos objetivos (Fama \& French, 2002).

A Tabela 5 evidencia as principais predições da tradeoff theory.

Tabela 5. Principais Predições da TOT

\begin{tabular}{|c|c|c|c|c|c|}
\hline $\begin{array}{l}\text { Variáveis de } \\
\text { Controle }\end{array}$ & Proxies & Dividendos & $\begin{array}{c}\text { Alavancagem } \\
\text { Financeira } \\
\text { (Valor } \\
\text { Contábil ou } \\
\text { BV) }\end{array}$ & $\begin{array}{l}\text { Alavancagem } \\
\text { Financeira } \\
\text { (Valor de } \\
\text { Mercado ou } \\
\text { MV) }\end{array}$ & Referência \\
\hline $\begin{array}{r}\text { 1. Rentabilidade } \\
\text { dos ativos (P) }\end{array}$ & $P=\frac{E B I T}{A}$ & $\begin{array}{l}\text { Empresas mais } \\
\text { rentáveis } \\
\text { pagam mais } \\
\text { dividendos }\end{array}$ & $\begin{array}{l}\text { Empresas mais } \\
\text { rentáveis têm } \\
\text { maior } \\
\text { alavancagem }\end{array}$ & & $\begin{array}{l}\text { Jensen e } \\
\text { Meckling } \\
(1976), \\
\text { Easterbroo } \\
\text { k (1984) e } \\
\text { Jensen } \\
(1986)\end{array}$ \\
\hline
\end{tabular}




\begin{tabular}{ll}
\hline $\begin{array}{l}\text { 2.Oportunidades } \\
\text { de } \\
\text { investimentos }\end{array}$ & $M T B=\frac{M V}{B V}$ \\
& \\
& \\
$\begin{array}{l}\text { 3.Volatilidade } \\
\text { dos lucros }\end{array}$ & $\begin{array}{l}\text { Desvio-padrão } \\
\text { do EBIT }\end{array}$ \\
$\begin{array}{ll}\text { 4.Escudo fiscal } \\
\text { de itens não } \\
\text { financeiros }\end{array}$ & $\begin{array}{l}\text { Despesas de } \\
\text { depreciação, } \\
\text { amortização e } \\
\text { exaustão. }\end{array}$
\end{tabular}

\section{Variáveis de Proxies Controle}

6.Tangibilidade dos ativos (T)

$\begin{array}{lll}\text { Controlando a } & \text { Controlando a } & \text { Controlando a } \\ \text { rentabilidade } & \text { rentabilidade } & \text { rentabilidade } \\ \text { dos ativos, } & \text { dos ativos, } & \text { dos ativos, } \\ \text { empresas com } & \text { empresas com } & \text { empresas com } \\ \text { mais } & \text { mais } & \text { mais } \\ \text { oportunidades } & \text { oportunidades } & \text { oportunidades } \\ \text { de } & \text { de } & \text { de } \\ \text { investimentos } & \text { investimentos } & \text { investimentos } \\ \text { pagam menos } & \text { têm menor } & \text { têm menor } \\ \text { dividendos } & \text { alavancagem } & \text { alavancagem }\end{array}$

Fama e

French

(2002)

DeAngelo e Masulis (1980) rentabilidade dos ativos, empresas com mais escudos fiscais não financeiros têm menor alavancagem

\section{Dividendos}

Alavancagem
Financeira
(Valor
Contábil ou
BV)
Empresas que
empregam
mais ativos
tangíveis têm
maior
alavancagem

\section{Alavancagem Financeira (Valor de Mercado ou MV)}

Harris e

Raviv

(1991) e

Rajan e

Zingales (1995)

Fonte: adaptação baseada em Fama e French (2002).

Em que:

EBIT: lucro antes dos juros e dos impostos;

Similarmente à POT, também enfrenta dificuldades do ponto de vista empírico, em razão dos pressupostos da TOT, relacionados aos impostos sobre os lucros, ou seja, as empresas com elevados níveis de rating de crédito, lucrativas e, consequentemente, pagadoras de impostos, evidenciam moderados níveis de endividamento (Myers, 2001).

Em resumo, as evidências empíricas apontam para uma correlação inversa entre lucratividade e endividamento, diferentemente do previsto pela TOT (Myers, 2001; Fama \& French, 2002).

Outra dificuldade da TOT refere-se à mensuração dos custos de financial distress, principalmente de custos indiretos relacionados, por exemplo, a perdas de clientes e às 
respectivas receitas, quando a credibilidade financeira de uma empresa é questionada em razão de um eminente risco de descontinuidade (Myers et al, 2017).

A despeito dos problemas da TOT, apesar da não evidenciação empírica relativa ao nível de endividamento das empresas lucrativas, outros estudos apontam que muitas empresas perseguem estrutura de capital alvo por meio da relação de dívida com patrimônio líquido com base no valor contábil dos ativos, conforme Harris e Jalilvand (1984).

\subsection{POT versus TOT}

Sanvicente, Bortoluzzo e Bortoluzzo (2017) apontam que a POT, diante da necessidade de recursos para financiar investimentos, trata da escolha entre retenção de lucros, emissão de dívida e emissão de ações, em um contexto de assimetria de informações entre os provedores de fundos. Também, segundo Sanvicente et al (2017), a principal premissa da TOT é a existência de imperfeições de mercado em decorrência de assimetria de informações entre administradores, acionistas e credores fazem com que as decisões de estrutura de capital sejam relevantes para a maximização do valor da empresa, ou seja, há uma estrutura ótima de capital.

Estudo de Kaveski, Zittei e Scarpin (2014), abordando empresas latino americanas, compreendendo Argentina, Brasil, Chile, Colômbia, México e Peru, observam que as empresas que empregam alto volume de ativos intangíveis possuem maior tendência e emprego de dívida e empresas mais rentáveis são menos endividadas, concluindo que estas empresas se apoiam tanto na POT quanto na TOT.

Do ponto de vista do mercado de capitais do Brasil, Nakamura et al (2007), considerando dados de companhias abertas brasileiras no período de 1999 a 2003, concluem que o padrão de financiamento segue a lógica do modelo POT.

Diferentemente, Araújo, Amaral e Iquiapaza (2008), analisando as companhias abertas brasileiras no período de 2000 a 2005, sugerem a possível existência de uma forma híbrida de POT e TOT quanto ao padrão de financiamento das empresas.

Em linha com Nakamura et al (2007), Medeiros e Daher (2008) concluem que, de acordo com o padrão de financiamento das empresas brasileiras no período de 1995 a 2002, a POT é aceita quase de forma forte, evidenciando a priorização do emprego de recursos internos, seguida de emissões de dívidas e, por último, da emissão de ações.

Corroborando estudos brasileiros anteriores, Nakamura et al (2013), ao analisarem as companhias abertas do Brasil no período de 1999 a 2004, obtêm resultados que sugerem que a POT é o padrão mais consistente de financiamento das empresas brasileiras.

Em linha com os estudos citados, Coelho (2015) conclui que há relativa similaridade entre empresas do Brasil, China, Índia e Paquistão no que tange as empresas com maior rentabilidade utilizarem menos recursos de terceiros, indicando a prevalência da POT.

Finalmente, Zeidan, Galil e Shapir (2018) investigaram empresas brasileiras de capital fechado e de pequeno e médio em 2013, concluindo que estas empresas seguem o modelo POT mesmo na presença de empréstimos subsidiados como os ofertados pelo Banco Nacional de Desenvolvimento Econômico e Social.

Por fim, Myers (2001) afirma que não há uma teoria universal sobre a escolha da proporção entre dívida e recursos próprios, entanto, há várias teorias usuais e condicionais, as quais sugerem que um modelo teórico pode ser mais aderente do que outro, quando submetido aos testes empíricos fundamentados em diferentes economias, mercados financeiros, empresas e vários períodos de tempo. 


\section{Método de Pesquisa}

Este estudo considera dados anuais obtidos das demonstrações financeiras consolidadas das companhias abertas brasileiras, abrangendo o período de 2010 a 2016 e coletados do Sistema Economática®.

Em linha com pesquisas correlatas, como Myers e Sunders (1999) e Frank e Goyal (2003), foram excluídas da base de dados as empresas classificadas como bancos, seguradoras e atividades relacionadas à intermediação financeira. Também foram excluídas da base de dados companhias em recuperação judicial, com receita operacional anual inferior a $\mathrm{R} \$ 300$ milhões (critério definido pelo Banco Nacional de Desenvolvimento Econômico e Social para segregar empresas de grande porte das demais), que não auferiram receita operacional em 2016 e que não apresentaram valor de mercado no final de 2016. Efetuados os devidos ajustes, a amostra final resulta em 199 companhias, conforme a tabela 6.

Tabela 6. Classificação setorial das empresas que compõe o estudo

\begin{tabular}{ll}
\hline Classificação setorial & Quantidade de empresas \\
${$\cline { 1 - 1 }$} }$ & 95 \\
Concessões de serviços públicos & 44 \\
Serviços em geral & 36 \\
Comércio & 12 \\
Construção civil & 12 \\
Total & 199 \\
\hline
\end{tabular}

Fonte: Elaboração própria.

O agrupamento em 5 categorias foi efetuado com base na classificação setorial NAICS (North American Industry Classification Sistem) das empresas objeto do estudo.

Similarmente aos estudos de Myers e Sunder (1999), Frank e Goyal (2003), Nakamura et al (2013), , são utilizados modelos econométricos de regressão com base em dados em painel.

Todos os dados foram corrigidos monetariamente pelo IPCA (IBGE) para a data base de 31 de dezembro de 2016. Seguindo a linha de Frank e Goyal (2003), objetivandocontrolar os diferentes portes das empresas da amostra, as variáveis são divididas pelo ativo total do mesmo período, exceto os logaritmos das receitas operacionais das empresas.

Os estudos sobre os modelos de regressão de dados em painel consideram dois modelos de regressão, a saber: modelo de efeitos fixos e modelo de efeitos aleatórios (Wooldridge, 2016; Gujarati \& Porter, 2011).

Gujarati e Porter (2011) apontam o teste de Hausmann para indicar se o modelo de efeitos fixos e o modelo de efeitos aleatórios não diferem substancialmente.

No teste de Hausmann, a hipótese nula é a de que os estimadores do modelo de efeito fixo e do modelo de efeitos aleatórios não são diferentes. Se a hipótese nula não for aceita, a conclusão é que o modelo de efeitos aleatórios não é adequado em razão de estes provavelmente estarem correlacionados com uma ou mais variáveis do modelo. Nesse caso, é aceito o modelo de efeitos fixos (Gujarati \& Porter, 2011). Conforme Torres-Reyna (2007), 
no teste de Hausman, se a probabilidade for menor do que 0,05 , rejeita-se a hipótese nula e consequentemente o modelo de efeitos fixos é considerado mais eficiente.

De acordo com Fávero, Belfiore, Takamatsu e Suzart (2014), os dados em painel providenciam maior quantidade de informação, maior variabilidade dos dados, menor colinearidade entre as variáveis, maior número de graus de liberdade e maior eficiência na estimação. A

Este estudo testa as predições teóricas da POT com base no modelo de Frank e Goyal (2003) e da POT conjuntamente com a TOT, com base no modelo de Rajan e Zingales (1995).

Ambos os modelos econométricos empregam variáveis de controle relacionadas à tangibilidade dos ativos, a oportunidades de crescimento, ao porte e à rentabilidade dos ativos, geralmente empregadas na literatura do gênero conforme aponta Vo (2017).

A Tabela 7 evidencia as variáveis de controle com as respectivas proxies empregadas nos modelos econométricos utilizados neste estudo e as respectivas relações com o grau de alavancagem financeira conforme as predições teóricas tanto da POT quanto da TOT.

Tabela 7. Variáveis de controle, proxies e relações esperadas em relação a POT e TOT

\begin{tabular}{|c|c|c|c|}
\hline Variáveis de Controle & Proxies & $\begin{array}{c}\text { Relações } \\
\text { Esperadas pela } \\
\text { POT }\end{array}$ & $\begin{array}{l}\text { Relações } \\
\text { Esperadas pela } \\
\text { TOT }\end{array}$ \\
\hline 1. Tangibilidade dos ativos (T) & $T_{i}=\frac{A T_{i}}{A_{i}}$ & Negativa & positiva \\
\hline $\begin{array}{l}\text { 2. Oportunidades de investimentos } \\
\text { (MTB) }\end{array}$ & $M T B_{i}=\frac{M V_{i}}{B V_{i}}$ & Negativa & negativa \\
\hline 3. Porte das empresas (LS) & $L S_{i}=\log R O_{i}$ & Positiva & positiva \\
\hline 4. Rentabilidade dos ativos $(\mathrm{P})$ & $P_{i}=\frac{E B I T_{i}}{A_{i}}$ & Negativa & positiva \\
\hline
\end{tabular}

Fonte: elaboração própria.

Em que:

AT: ativos tangíveis;

A: total dos ativos;

EBIT: lucro antes dos juros e dos impostos;

$M V$ : valor de mercado da empresa;

$B V$ : valor contábil da empresa;

$L S$ : logaritmo das receitas operacionais.

Sobre a mensuração da tangibilidade dos ativos, a literatura de finanças usualmente considera a proporção do ativo imobilizado mais os estoques em relação aos ativos totais. B buscando aperfeiçoar a mensuração das variáveis de controle, este estudo inclui nesse cálculo outros ativos tangíveis tais como propriedades para investimento, ativos biológicos e estoques, reconhecidos tanto no ativo não circulante quanto no ativo circulante dos balanços patrimoniais.

Quanto à estrutura de capitais, a literatura de finanças emprega o conceito de dívida de longo prazo e o de dívida total. Myers e Sunder (1999) consideram somente a dívida de longo prazo. Entretanto, corroborando a utilização das dívidas de curto prazo na estrutura de capital, há os estudos de Rajan e Zingales (1995), Nakamura et al (2007) e Medeiros e Daher (2008). 
Este estudo também considera a estrutura de capital como composta por recursos de curto e longo prazos.

A seguir são descritos os modelos econométricos empregados, ressaltando-se que nas equações dos modelos econométricos, $i$ significa os elementos da amostra (companhias), e $t$ os períodos anuais.

\section{Modelo Pecking Order Theory}

Frank e Goyal (2003) empregam como base modelo econométrico evidenciado na equação (1) para fins de teste empírico da POT:

$\Delta D_{i, t}=\propto+\beta D E F_{i, t}+\varepsilon_{i, t}$

Em que:

$\Delta D_{i, t}$ : emissão de dívida;

$\propto$ : intercepto da equação;

$\beta$ : coeficiente da equação;

$D E F_{i, t}$ : déficit de caixa da companhia; e

$\varepsilon_{i, t}:$ termos dos erros, tal que $\varepsilon_{t} \sim N\left(0, \sigma^{2}\right)$.

O modelo da equação (1) considera a obtenção de financiamentos como variável dependente e o déficit (necessidade de caixa) como variável explicativa, buscando testar empiricamente a relação entre ambas variáveis.

O déficit de caixa, considerando a adaptação do modelo de Myers e Sunders (1999), efetuada por Frank e Goyal (2003), é calculado com base na equação (2):

$D E F_{i, t}=D I V_{i, t}+I_{i, t}+\Delta W_{i, t}-C_{i, t}$

Em que

$D E F_{i, t}:$ déficit de caixa;

$D I V_{i, t}$ : dividendos e juros sobre o capital próprios pagos;

$I_{i, t}$ : investimentos líquidos realizados, que significam o desembolso de caixa para a obtenção de ativos não circulantes, menos o caixa obtido por meio de alienações de ativos semelhantes; $\Delta W_{i, t}$ : variação do capital circulante líquido da companhia $i$ no ano $t$; e

$C_{i, t}$ : fluxo de caixa gerado pelas operações após o pagamento de juros e dos impostos sobre lucro.

Frank e Goyal (2003) incluem no modelo econométrico, evidenciado pela equação (1), variáveis de controle dando origem à equação (3):

$\Delta D_{i, t}=\propto+\beta_{\Delta T} \Delta T_{i, t}+\beta_{\Delta M T B} \Delta M T B_{i, t}+\beta_{\Delta L S} \Delta L S_{i, t}+\beta_{\Delta P} \Delta P_{i, t}+\beta_{\Delta D E F} D E F_{i, t}+\varepsilon_{i, t}$

Em que:

$\Delta D_{i, t}:$ emissão de dívida;

$\propto$ : intercepto da equação;

$\beta_{\Delta T}$ : coeficiente da variável $\Delta T_{i, t}$; 
$\Delta T_{i, t}$ : primeira diferença entre o valor do período $t$, menos o valor do período $t-1$ da tangibilidade dos ativos.

$\beta_{\triangle M T B}$ : coeficiente da variável $\triangle M T B_{i, t}$

$\triangle M T B_{i, t}$ : primeira diferença entre o valor do período $t$, menos o valor do período $\mathrm{t}-1 \mathrm{da}$ relação entre o valor de mercado da empresa e o valor contábil dos ativos;

$\beta_{L S}$ : coeficiente da variável $\Delta L S_{i, t}$;

$\Delta L S_{i, t}$ : primeira diferença entre o valor do período $t$, menos o valor do período $t-1$ do logaritmo das receitas operacionais;

$\beta_{\Delta P}$ : coeficiente da variável $\Delta P_{i, t}$

$\Delta P_{i, t}$ : primeira diferença entre o valor do período $t$, menos o valor do período $t-1$ da rentabilidade dos ativos.

$\beta_{\triangle D E F}$ : coeficiente da variável $D E F_{i, t}$;

$D E F_{i, t}$ : déficit de caixa tal como definido pela equação (1); e

$\varepsilon_{i, t}$ : termos dos erros, tal que $\varepsilon_{t} \sim N\left(0, \sigma^{2}\right)$.

Quanto ao teste da relação entre emissão de ações para fins de cobertura do déficit financeiro, a equação (1) é adaptada, dando origem à equação (4):

$\Delta E_{i, t}=\propto+\beta D E F_{i, t}+\varepsilon_{i, t}$

Em que:

$\Delta E_{i, t}$ : emissão líquida de ações (emissão de ações, menos recompra de ações).

$\mathrm{E}$ as demais variáveis são as evidenciadas similarmente com base na equação (1).

\section{Modelo Tradeoff Theory}

De acordo com a TOT, administradores buscam um nível ótimo de estrutura de capital para as empresas (Myers \& Sunders, 1999).

Assim sendo, as oscilações do nível de endividamento de uma empresa, para além ou aquém do que é considerado o nível ótimo de uma estrutura de capital, seriam compensadas por movimentos opostos, em convergência ao referido ponto ótimo (Myers \& Sunders, 1999).

Entretanto, um dos desafios da análise empírica da TOT é a definição do ponto ótimo da estrutura de capital. Conforme apontam Myers e Sunders (1999), dívida alvo não é observável, o que exige dos pesquisadores um esforço adicional de plausibilidade para a seleção dos critérios de avaliação.

Posto isto, dentro de esforço de testar empiricamente o modelo TOT, similarmente a outros estudos do gênero, é considerada a adaptação do modelo de Rajan e Zingales (1995), analisando a relação do total da dívida com as variáveis de controle, sem recorrer a proxies de endividamento alvo.

Os sinais obtidos do modelo de Rajan e Zingales (1995) permitem um teste simultâneo, tanto da POT quanto da TOT.

O referido modelo dá origem à equação (5):

$D_{i, t}=\propto+\beta_{T} T_{i, t}+\beta_{M T B} M T B_{i, t}+\beta_{L S} L S_{i, t}+\beta_{P} P_{i, t}+\varepsilon_{i, t}$

Em que: 
$D_{i, t}:$ saldo total de dívida;

$\propto:$ intercepto da equação;

$\beta_{T}$ : coeficiente da variável $T_{i, t}$;

$T_{i, t}$ : tangibilidade dos ativos.

$\beta_{M T B}$ : coeficiente da variável $M T B_{i, t}$;

$M T B_{i, t}$ : relação entre o valor de mercado e o valor contábil da empresa;

$\beta_{L S}$ : coeficiente da variável $L S_{i, t}$;

$L S_{i, t}$ : logaritmo da receita operacional;

$\beta_{P}$ : coeficiente da variável $P_{i, t}$;

$P_{i, t}:$ rentabilidade dos ativos;

$\varepsilon_{i, t}:$ termos dos erros, tal que $\varepsilon_{t} \sim N\left(0, \sigma^{2}\right)$.

\section{Análise dos Resultados}

A Tabela 7 evidencia o teste da POT, sem o emprego de variáveis de controle, conforme previsto na equação (1) e na equação (4).

Os resultados obtidos por meio da equação (1) apontam que os déficits são substancialmente correlacionados com a emissão de dívidas $\left(R^{2}=0,574\right)$ e significativos a um nível de $1 \%$.

Quanto a equação (4), embora os coeficientes sejam significativos a 1\%, o nível de correlação é significativamente inferior ao obtido por meio da equação (1).

Os resultados obtidos por meio da equação (1) e da equação (4) sugerem a prevalência do financiamento da necessidade de recursos (déficit) por meio de emissão de dívidas, corroborando o modelo POT.

Tabela 8. Teste da POT

\begin{tabular}{|c|c|c|c|c|}
\hline & \multicolumn{2}{|c|}{$\begin{array}{l}\text { Emissão líquida de ações } \\
\text { Modelo da equação (4) }\end{array}$} & \multicolumn{2}{|c|}{$\begin{array}{c}\text { Emissão líquida de dívida } \\
\text { Modelo da equação (1) }\end{array}$} \\
\hline & Efeitos Fixos & Efeitos Aleatórios & Efeitos Fixos & Efeitos Aleatórios \\
\hline $\begin{array}{l}\text { Variável } \\
\text { explanatória }\end{array}$ & $\begin{array}{l}\text { Coeficientes } \\
(P \text {-Valor })\end{array}$ & $\begin{array}{l}\text { Coeficientes } \\
(P \text {-Valor })\end{array}$ & $\begin{array}{l}\text { Coeficientes } \\
(P \text {-Valor })\end{array}$ & $\begin{array}{l}\text { Coeficientes } \\
(P \text {-Valor) }\end{array}$ \\
\hline Déficit & $\begin{array}{l}0,1483^{* * * *} \\
(0,000)\end{array}$ & $\begin{array}{l}0,1482 * * * \\
(0,000)\end{array}$ & $\begin{array}{l}0,6712 * * * \\
(0,000)\end{array}$ & $\begin{array}{l}0,6732 * * * \\
(0,000)\end{array}$ \\
\hline Intercepto & $\begin{array}{l}0,0092 * * * \\
(0,000)\end{array}$ & $\begin{array}{l}0,0092 * * * \\
(0,000)\end{array}$ & $\begin{array}{l}-0,0067 * * * \\
(0,004)\end{array}$ & $\begin{array}{l}-0,0067 * \\
(0,070)\end{array}$ \\
\hline$R^{2}$ & 0,0880 & 0,0880 & 0,5740 & 0,5740 \\
\hline Hausmann & & 98436,1 & & 1,47 \\
\hline Probabilidade & & Prob. $=(0,0000$ & & Prob. $=(0,2258)$ \\
\hline Teste F & & Prob $>F=0,000$ & & Prob $>F=0,0000$ \\
\hline Observações & & 1.17 & & 1.174 \\
\hline
\end{tabular}

Fonte: elaboração própria.

(*) estatisticamente significativo a $10 \%$.

(**) estatisticamente significativo a $5 \%$.

$(* * *)$ estatisticamente significativo a $1 \%$. 
Na sequência, o modelo POT é testado com base na equação (3), incorporando as variáveis de controle evidenciadas na Tabela 7.

Quanto à Tabela 7, as variáveis de controle utilizadas na equação (3), com base nos estudos de Harris e Raviv (1991) e Rajan e Zingales (1995) e em linha com o modelo de Frank e Goyal (2003), testam apenas a relação do déficit com a emissão de dívidas, não sendo empregadas na relação entre déficit e a emissão de ações.

Tabela 9. Teste da POT: Relação da dívida com as variáveis explanatórias

\section{Emissão líquida de dívidas}

Equação (3)

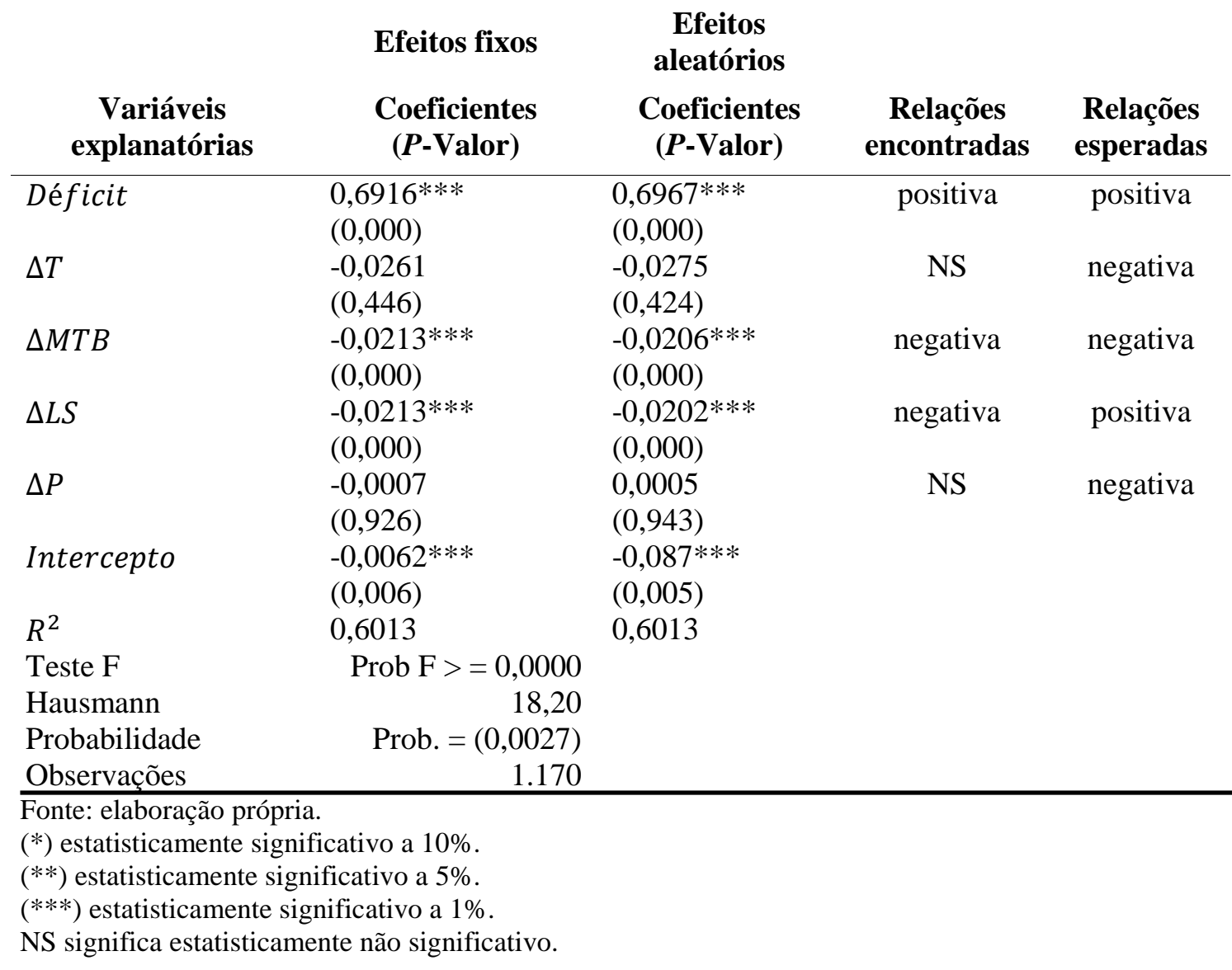

Conforme a Tabela 9 indica, a variável explanatória Déficit é estatisticamente significativa a $1 \%$ com coeficiente acima de 0,69, sugerindo novamente a importância da emissão de dívidas no financiamento dos déficits das empresas.

A relação entre o valor de mercado e o valor contábil das empresas, proxy de oportunidades de crescimento por meio de investimentos também é significativa e $1 \%$ e com sinal negativo em relação a emissão de dívida, em linha com o modelo POT.

Quanto as demais variáveis explanatórias, no caso a primeira diferença da tangibilidade dos ativos $(\Delta T)$ e a primeira diferença da rentabilidade dos ativos $(\Delta P)$, não são estatisticamente significativas. Quanto a primeira diferença do porte das empresas $(\Delta L S)$ mostrou-se negativamente relacionado com o endividamento, não confirmando a predição da POT. 
Em que pese as duas variáveis não estatisticamente significativas, o Teste $\mathrm{F}$ que os coeficientes do modelo são diferentes de zero.

Dando prosseguimento aos testes estatísticos, a Tabela 10 evidencia os resultados obtidos com base no modelo de Rajan e Zingales (1995), com o emprego das variáveis de controle indicadas na Tabela 7.

Tabela 10. Relação da dívida com variáveis explanatórias de controle conforme equação (5)

\begin{tabular}{|c|c|c|c|c|c|}
\hline $\begin{array}{c}\text { Variáveis } \\
\text { explanatórias }\end{array}$ & $\begin{array}{l}\text { Efeitos fixos } \\
\text { Coeficientes } \\
(P \text {-Valor })\end{array}$ & $\begin{array}{l}\text { Efeitos } \\
\text { aleatórios } \\
\text { Coeficientes } \\
(P \text {-Valor })\end{array}$ & $\begin{array}{c}\text { Relações } \\
\text { encontradas }\end{array}$ & $\begin{array}{c}\text { Relações } \\
\text { esperadas } \\
\text { POT }\end{array}$ & $\begin{array}{c}\text { Relações } \\
\text { esperadas } \\
\text { TOT }\end{array}$ \\
\hline$T$ & $\begin{array}{l}0,0589 * \\
(0,061)\end{array}$ & $\begin{array}{l}0,0505^{*} \\
(0,099)\end{array}$ & positiva & negativa & positiva \\
\hline MTB & $\begin{array}{l}0,0451 * * * \\
(0,000)\end{array}$ & $\begin{array}{l}0,0406 * * * \\
(0,000)\end{array}$ & positiva & negativa & negativa \\
\hline$L S$ & $\begin{array}{l}-0,0437 * * * \\
(0,000)\end{array}$ & $\begin{array}{l}-0,0452 * * * \\
(0,000)\end{array}$ & negativa & positiva & positiva \\
\hline$P$ & $\begin{array}{l}-0,2021 * * * \\
(0,000)\end{array}$ & $\begin{array}{l}-0,207 * * * \\
(0,000)\end{array}$ & negativa & negativa & positiva \\
\hline Intercepto & $\begin{array}{l}0,5381 * * * \\
(0,000)\end{array}$ & $\begin{array}{l}0,5577 * * * \\
(0,000)\end{array}$ & & & \\
\hline$R^{2}$ & 0,0539 & 0,0541 & & & \\
\hline
\end{tabular}

Teste F

Prob $F>=0,0000$

Hausmann

15,77

Probabilidade

Prob. $=(0,0033)$

Observações

1.356

Fonte: Elaboração própria.

(*) estatisticamente significativo a $10 \%$.

(**) estatisticamente significativo a $5 \%$.

(***) estatisticamente significativo a $1 \%$.

NS significa estatisticamente não significativo.

Os resultados da Tabela 10 indicam que todos os coeficientes são estatisticamente significativos, entretanto, os sinais obtidos não sugerem a predominância do modelo TOT em relação ao POT e vice-versa. Embora a variável T aponte para o mesmo sinal da relação esperada com o modelo TOT, a variável P se alinha com o modelo POT. As demais variáveis não evidenciam sinais em consonância com os modelos teóricos objeto de análise.

\section{Conclusões}

Os resultados obtidos por este estudo sugerem que o financiamento dos déficits financeiros das companhias abertas brasileiras é financiado por emissão de dívidas, indicando 
que a estrutura de capital das companhias abertas brasileiras segue o modelo POT, em linha com os resultados obtidos por Medeiros e Daher (2008) e Nakamura et al (2013).

Os resultados obtidos também sugerem que a estrutura de capital das companhias abertas brasileiras não segue predições do modelo TOT, conforme as variáveis de controle empregadas no Modelo de Rajan e Zingales (1995).

Quanto a contribuição deste estudo, este explora o emprego de dados obtidos por meio das demonstrações financeiras no padrão IFRS, abrindo perspectiva para comparação de estudos relativos a empresas brasileiras com as de outros países que adotam o padrão internacional de contabilidade. Este estudo também contribui para o entendimento do padrão de financiamento das companhias abertas brasileiras, podendo auxiliar na formulação de políticas públicas relacionadas ao mercado de capitais brasileiro.

Cumpre salientar possíveis limitações dessa pesquisa, notadamente, a reduzida quantidade de empresas em razão das dimensões do mercado de capitais no Brasil e do emprego de uma base de dados limitada ao período de 2010 a 2016 a fim de preservar a homogeneidade dos dados..

Sobre estudos futuros, em linha com o estudo de Zeidan et al (2018), sugere-se que as empresas brasileiras de capital fechado, de pequeno e médio porte, continuem sendo objeto de estudos. Kumar et al (2017) corroboram a importância das pequenas e médias empresas em razão da sua importância para o crescimento dos países em desenvolvimento e sugerem que fatores como características de acionistas e administradores tais como propensão ao risco, educação, e experiência profissional, também sejam estudados.

Estudos futuros também poderiam explorar a estrutura de capital de empresas com diferentes níveis de governança corporativa e eventuais impactos dos custos de ofertas públicas de ações e de emissões de dívidas em outros países e no mercado de capitais brasileiro.

\section{REFERÊNCIAS}

Araújo, M. S. B., Amaral, H. F., \& Iquiapaza, R. A. (2008). Testando as Previsões da Pecking Order Theory no Financiamento das Empresas Brasileiras: Uma Nova Metodologia. RAM. Revista de Administração Mackenzie. 9(3), 157-183.

Banco Nacional de Desenvolvimento Econômico e Social. (2017). Disponível em: <www.bndes.gov.br>. Acesso em: 15/07/2017.

Coelho, E. G. (2015). Estrutura de Capital: Um estudo bibliométrico dos reflexos de seus determinantes. In Congresso USP de Contabilidade e Controladoria, São Paulo, SP, Brasil, XV.

Comissão de Valores Mobiliários. (2017). Boletim de Mercado. 42, 1-12.

De Angelo, H., \& Masulis, R. W. (1980). Optimal Capital Structure under Personal and Corporate Taxation. Journal of Financial Economics, 8(1), 3-27.

Easterbrook, F. H. (1984). Two Agency-Cost Explanation of Dividends. The American Economic Review, 74(4), 650-659.

Economatica®. www.economatica.com.br. Acesso em 15/07/2017. 
Fama, E. F. (1984). Agency Problems and the Theory of the Firm. The Journal of Political Economy, 58, 288-307.

Fama, E. F., \& French, K. R. (2002). Testing Trade-off and Pecking Order Predictions about Dividends and Debt. The Review of Financial Studies, 15(1), 1-33..

Financing decisions: who issues stock? (2005). Journal of Financial Economics, 76(3), 549-582.

Fávero, L. P.; Belfiore, P.; Takamatsu, R. e Suzart, J. (2014) Métodos Quantitativos com Stata (Cap. 9, pp. 223-241). Rio de Janeiro: Elsevier.

Frank, M. Z., \& Goyal, V. K. (2003). Testing the pecking order theory of capital structure. Journal of Financial Economics, 67(2), 217-248.

Graham, J. R., Leary, M. T., \& Roberts, M. R. (2015). A century of capital structure: The leveraging of corporate America. Journal of Financial Economics, 118(3), 658-683.

Gujarati, D. N., \& Porter, D. C. (2011). Econometria Básica, 5. ed. (Cap. 16, pp. 588-610): Porto Alegre: McGraw Hill Bookman.

Harris, M., \& Haviv, A. (1991). The Theory of Capital Structure. The Journal of Finance, 46(1), 297-355.

Instituto Assaf. Disponível em: <www.institutoassaf.com.br>. Acesso em: 15/07/2017.

Jalilvand, A., \& Harris, R. S. (1984). Corporate Behavior in Adjusting to Capital Structure and Dividend Targets: An Econometric Study. The Journal of Finance, 39(1), 127-145.

Jensen, M. C. (1986). Agency costs of free cash flow, corporate finance and takeovers. The American Economic Review, 76(2), 323-329.

Jensen, M. C., \& Meckling, W. H. (1976). Theory of the Firm: Managerial Behavior, Agency Costs and Ownership Structure. Journal of Financial Economics, 3(4), 305-360.

Kaveski, I. D. S., Zittei, M. V. M.; \& Scarpin. J (2014). Tradeoff e Pecking Order - Uma Análise das Empresas de Capital Aberto da América Latina. In Congresso USP Contabilidade e Controladoria, São Paulo, SP, Brasil, XIV.

Kumar, S., Colombage, S., Rao, P. (2017). Research on capital structure determinants: a review and future directions. International Journal of Managerial Finance, 13(2), 106132.

Medeiros, O. R., \& Daher, C. (2008). Testando Teorias Alternativas sobre a Estrutura de Capital nas Empresas Brasileiras. RAC, v. 12(1), 177-199. 
Modigliani, F., \& Miller, M. H. (1958). The Cost of Capital, Corporate Finance, and the Theory of Investment. The American Economic Review, 48(3), 261-297.

. (1963). Corporate Income Taxes and the Cost of Capital: A Correction. The American Economic Review, 53(3), 443-453.

Myers, S. C. (2001). Capital Structure. The Journal of Economic Perspectives, 15(2), 81-102.

Myers, S. C., Allen, F., \& Brealey, R. A. (2017). Principles of Corporate Finance (Cap. 34, pp. 887-890), $12^{\text {th }}$ ed. New York: McGraw Hill.

Myers, S. C., \& Majluf, N. S. (1984). Corporate Finance and Investment Decisions When Firms Have Information That Investors Do Not Have. Journal of Financial Economics, $13(2), 187-221$.

Myers, S. C., \& Shyam-Sunder, L. (1999). Testing static tradeoff against pecking order models of capital structure. Journal of Financial Economics, 51(2), 219-244.

Nakamura, W. T., Correa, C. A., \& Basso, L. F. C. (2013). A Estrutura de Capital das Maiores Empresas Brasileiras: Análise Empírica das Teorias de Pecking Order e TradeOff, Usando Panel Data. RAM. Revista de Administração Mackenzie, 14(4), 106-133.

Nakamura, W., Martin, D. M. L., Forte, D., Carvalho Filho, A. F., Costa, A. C. F., Amaral, A. C. (2007). Determinantes de Estrutura de Capital no Mercado Brasileiro - Análise de Regressão com Painel de Dados no Período 1999-2003. Revista Contabilidade e Finanças, 18(44), 72-85.

Nisiyama, E. K. \& Nakamura, W. T. (2015). Pesquisas Internacionais Recentes em Estrutura de Capital. Revista de Administração de Roraima, 5(1), 105.

Oztekin, O. (2015). Capital Structure Decisions around the World: Which Factors Are Reliably Important? Journal of Financial And Quantitative Analysis, 50(3), 301-323.

Rajan, R. G., \& Zingales, L. (1995). What Do We Know about Capital Structure? Some Evidence from International Data. Journal of Finance, 50(5), 1421-1460.

Sanvicente, A. Z., Bortoluzzo, A. B., \& Bortoluzzo, M. M. (2017). Capital structure determinants of financially constrained and unconstrained firms. São Paulo School of Economics, Working paper 451. Fundação Getúlio Vargas.

Titman, S., \& Wessels, R. (1988). The Determinants of Capital Structure Choice. Journal of Finance, 43(1) 1-19.

Torres-Reyna, O. (2007). Panel Data Analysis Fixed and Randon Effects. Disponível em: <dss.princeton.edu/training>. Acesso em: 16/07/2017. 
Vo, X. V. (2017). Determinants of capital structure in emerging markets: Evidence from Vietnam. Research in International Business and Finance, 40(1), 105-113.

Wooldridge, J. M. (2016). Introdução à Econometria - Uma Abordagem Moderna , 3. ed.(Cap. 13, pp. 492-521) São Paulo: Cengage.

Zeidan, R.; Galil, K.; \& Shapir, Offer (2018). Do ultimate owners follow pecking order theory? The Quarterly Review of Economics and Finance, 67, 45-50. 